\title{
A ABORDAGEM DE SHIMPI PARA GESTÃO DE RISCOS
}

\author{
Alexsandro Broedel Lopes \\ Professor Doutor do Depto. de Contabilidade e Atuária da FEA-USP \\ E-mail: broedel@usp.br \\ L. Nelson Carvalho \\ Professor Doutor do Depto. de Contabilidade e Atuária da FEA-USP \\ E-mail: Inelson@usp.br \\ Aridelmo José Campanharo Teixeira \\ Professor Doutor e Coordenador do Programa de Mestrado da FUCAPE - ES \\ E-mail: aridelmo@fucape.br
}

\section{RESUMO}

Este artigo discute a metodologia proposta por Shimpi para a gestão de riscos baseada nos custos de transação e demais fricções existentes nos mercados. $\mathrm{O}$ artigo demonstra que a gestão de riscos é um instrumento para a redução dos custos de transação e, como tal, pode ser substituída, ou melhorada, por práticas não convencionais. $O$ artigo é concluído com recomendações para o desenvolvimento e implementação de modelos e técnicas de gestão de riscos que considerem a fundamentação econômica apresentada. $O$ trabalho não apresenta conclusões analíticas (dentro do paradigma positivo de pesquisa). Essa visão alternativa fornece um novo caminho para o desenvolvimento de pesquisas na área.

Palavras-chave: Gestão de riscos; custos de transação; alocação de capital; administração de resultados; gestão baseada no risco.

\section{ABSTRACT}

This paper presents the methodology proposed by Shimpi for risk management practices based on transaction costs and other market frictions. The paper demonstrates that risk management is a tool for reducing transactions costs and, as such, it can be replaced or improved by non-conventional practices. We present some recommendations for the development and implementation of risk management models and techniques that consider the economic foundation presented. This paper does not present any analytical conclusions (like the ones usually found in positive-based research). This new approach provides an alternative path towards new investigations in the field.

Keywords: Risk management; transaction costs; capital allocation; earnings management; risk-based management. 


\section{INTRODUÇÃO}

O controle gerencial de instrumentos financeiros, especialmente derivativos em instituições financeiras e não-financeiras, desenvolveu-se acentuadamente durante a década de 1990 (JORION, 1996). Esse desenvolvimento foi quantitativo, com maior número de instituições utilizando sistemas de controle especialmente desenvolvidos para as operações com derivativos, e qualitativo, com o aumento da sofisticação das técnicas e procedimentos adotados. Esses desenvolvimentos podem ser analisados sob duas óticas complementares: a conceitual e institucional.

\section{VISÃO CONCEITUAL}

Do ponto de vista conceitual, muitos avanços foram realizados na tentativa de entender o papel da gestão de riscos e os mecanismos de controle na teoria da firma. Tradicionalmente, segundo Vaughan (1997), as práticas de gestão de riscos eram de difícil justificativa uma vez que, assumindo a neutralidade em relação ao risco da empresa, essa estaria em melhor situação econômica se arcasse sozinha com os riscos de suas ações e exposições ao invés de buscar proteção no mercado. Essa piora na situação da empresa deve-se ao lucro do segurador ou intermediário financeiro presente na operação. Nesse mundo idealizado, as organizações assumiriam integralmente seus riscos, não havendo a necessidade de buscar o mercado financeiro e segurador para obter proteção.

Naturalmente, essa descrição simplificada não reflete adequadamente a realidade das organizações, uma vez que as atividades de proteção e hedge são amplamente praticadas pelas empresas. Cabe ressaltar que a ausência de um entendimento adequado da natureza das atividades de proteção é crítica para a gestão profissional de riscos das empresas. Como um processo pode ser otimizado e implementado sem o adequado entendimento de sua natureza? O entendimento do papel da gestão de riscos dentro da teoria da firma não é uma mera curiosidade acadêmica. Esse entendimento é fundamental para a gestão da firma. A realidade empresarial é prova indiscutível da relevância das atividades ligadas à gestão de riscos nas organizações modernas, sejam elas financeiras ou não.
Dentro dessa perspectiva, alguns autores começaram a contextualizar a gestão de riscos dentro das atividades funcionais das empresas na busca por uma justificativa conceitual para essa atividade. Autores, como Barton (2001), analisaram o impacto do tratamento contábil dos derivativos nas atividades de hedge das empresas. Esse autor parte da constatação de que a administração do lucro, buscando a redução de sua volatilidade, revestese de uma das atividades mais importantes das empresas modernas, consumindo grande parte do tempo e da atenção de seus principais executivos. Como administração do lucro entende-se a gestão dos accruals (ajustes advindos do regime de competência) discricionários da empresa, para que o lucro não fique distante das expectativas dos analistas. De forma objetiva, trata-se de um jogo de percepção com o mercado. Os administradores não querem que a empresa apresente lucros menores do que o esperado para não frustrar as expectativas do mercado, conseqüentemente reduzem os preços das ações da empresa e os bônus e demais benefícios que esses administradores recebem. Por outro lado, esses administradores também não querem que a empresa apresente lucros muito superiores às expectativas para não gerar cobranças excessivas nos anos seguintes que demandariam esforços adicionais para sua consecução. Essa demanda por resultados 'suavizados' leva as empresas a utilizarem instrumentos financeiros para administrar os lucros contábeis além da utilização tradicional de hedge do fluxo do caixa (KOTHARI, 2000).

Outros autores, como Doherty (2000), têm oferecido um arcabouço diferente para justificar a gestão de riscos nas empresas. Esses autores trabaIham com uma crítica à idéia de mercados perfeitos e eficientes nos quais não existem custos de transação e de insolvência. Na inexistência de tais custos, reza a teoria clássica, a empresa irá sempre preferir projetos com maior valor presente líquido (VPL), para um dado nível de risco. No entanto, na prática, a possibilidade de insolvência e os elevados custos relacionados (reputação, honorários advocatícios etc) criam conflitos de interesse entre acionistas e credores. Vamos analisar o exemplo da empresa Boa Falência S/A representada esquematicamente pelo balanço patrimonial a seguir: 


\begin{tabular}{|c|c|}
\hline \multicolumn{2}{|l|}{$\begin{array}{c}\text { Empresa Boa Falência S/A } \\
\text { Balanço Patrimonial em 31.12.X0 }\end{array}$} \\
\hline Ativo & \\
\hline Caixa & 20.000 \\
\hline Máquinas e Equipamentos & 100.000 \\
\hline Total do Ativo & 120.000 \\
\hline Passivo & \\
\hline Credores Diversos & 150.000 \\
\hline Patrimônio Líquido & $(30.000)$ \\
\hline Total do Passivo & 120.000 \\
\hline
\end{tabular}

Suponha que as dívidas devam ser pagas integralmente em 31.03.X1 e que os valores de máquinas e equipamentos estejam a mercado (mesmo no caso da liquidação da empresa). Assuma, agora, que a empresa somente possui dois projetos, excludentes, que podem ser realizados até 31.03.X1 para conseguir os recursos e evitar a falência. No projeto $A$, a empresa tem um fluxo de caixa líquido garantido de $\$ 20.000$, isto é, sem risco. No projeto B, a empresa tem duas possibilidades: um fluxo de caixa líquido de $\$ 0$ com $90 \%$ de chance e um fluxo de caixa líquido de $\$ 100.000$ com $10 \%$ de chance. Dessa forma, o valor presente líquido do projeto $B$ é $\$ 0 * 0,90+100.000^{*} 0,10=\$ 10.000$. Qual projeto é o mais adequado?

A resposta dependerá de quais interesses sejam considerados como prioritários. O projeto A garante um fluxo de caixa líquido de $\$ 20.000$ que poderia ser usado para pagar parte dos credores, mas não evitaria que a empresa fosse liquidada. O projeto A prejudicaria os administradores que, provavelmente, perderiam seus empregos. Já o projeto B com VPL menor seria mais interessante para os administradores que, pelo menos, teriam uma chance de recuperar a empresa, mantendo seus empregos. Os credores seriam prejudicados pelo projeto $\mathrm{B}$, pois teriam uma chance menor de receber seus recursos de volta.

Nesse exemplo, vemos claramente como os interesses dos agentes ligados à empresa podem ser contrastantes. E os acionistas? Parece claro que, nesse exemplo, eles optariam pelo projeto $B$ que daria a eles uma chance de manter o controle da empresa. O projeto A não seria interessante para eles, pois estaria somente contribuindo para o pagamento dos credores. Como esses acionistas não têm responsabilidade por tais pagamentos, por que se preocupar?
A possibilidade de insolvência, compreendida como a incapacidade de obtenção infinita de recursos pelas empresas, altera a gestão normal da mesma. A teoria clássica de finanças apontaria o projeto $\mathrm{A}$ como o mais indicado devido à regra do VPL, apesar de ser prejudicial aos administradores. Para evitar tal conflito, os credores, normalmente, impõem cláusulas restritivas às ações dos administradores da empresa nos contratos de financiamento. $O$ objetivo de tais restrições é justamente evitar ações dos administradores que sejam lesivas aos interesses dos credores.

Qual o papel da gestão de riscos nesse contexto? A despeito de, na maioria das vezes, a gestão de riscos reduzir o valor da empresa, uma vez que os prêmios cobrados pelas seguradoras ou intermediários financeiros são superiores ao valor da perda esperada, ela também trabalha na outra mão: reduz a possibilidade de insolvência. Dessa forma, a gestão de riscos afeta, diretamente, o conflito de interesses apresentado acima, levando administradores a buscarem proteção, mesmo que seja às custas do valor da empresa.

As constatações apresentadas possuem implicações diretas nas práticas e políticas de risco empregadas pelas empresas. Como o risco falimentar é determinante para a utilização ou não de técnicas de gestão de riscos, o ambiente no qual a empresa atua terá influência marcante. Características dos mercados locais em termos de governança corporativa e arcabouço legal têm impacto nas probabilidades de insolvência, por intermédio do acesso das empresas a fontes de financiamento. Dentro da estrutura apresentada, empresas que atuam em mercados mais eficientes, com maior disponibilidade de recursos para alocação intertemporal, terão comportamento, em relação ao risco, mais flexível e as técnicas de gestão de riscos serão utilizadas menos intensamente, ou, pelos menos, mais racionalmente.

\section{VISÃO INSTITUCIONAL}

Além do aspecto teórico e conceitual, algumas questões institucionais influenciaram a forma como as empresas passaram a enxergar a gestão de riscos. Os grandes desastres financeiros tiveram contribuição significativa nesse processo. Instituições financeiras tradicionais como o banco inglês Barings, fundos de investimento com performance irrefutável 
como o Long Term Capital Management, empresas tradicionais como a Procter \& Gamble, administrações públicas como o Orange County, são apenas alguns exemplos. A questão institucional possui grande impacto nas perspectivas dos agentes econômicos sobre o problema.

Dentro dessa nova problemática, alguns autores têm proposto modelos de gestão de risco diferenciados em relação aos tradicionalmente aplicados. Doherty (2000) propôs a idéia de que a gestão de riscos deva ser uma atividade integrada. Segundo esse autor, a existência da gestão de riscos nas empresas pode ser explicada por intermédio dos custos de transação. As empresas não vivem em um mundo ideal sem custos de transação, impostos e conflitos entre os agentes econômicos. O risco que a empresa assume impacta, de forma diferente, nos acionistas e credores, por exemplo. Os acionistas tendem a preferir projetos mais arriscados porque eles podem receber o máximo na alta e simplesmente decretar a insolvência da empresa na baixa. Essa possibilidade é percebida pelos credores que impõem uma série de condições por intermédio de cláusulas restritivas nos contratos, elevando, assim, o custo dos recursos no mercado. A gestão de riscos é uma forma de reduzir o impacto desses custos de transação.

A ausência de uma gestão de riscos adequada pode levar a empresa a perder as opções sobre novos investimentos de valor presente líquido positivo (VPL), pois a ocorrência de um evento, sem a devida proteção, pode levar a empresa a consumir os recursos internos para cobrir as perdas, reduzindo os recursos disponíveis para novos investimentos. Assim, a reação dos administradores perante o risco também é variável importante. Tradicionalmente, assume-se que os gestores são avessos ao risco e pouco diversificados, enquanto os acionistas são mais diversificados. A gestão de riscos também pode ser usada para resolver esse conflito (DOHERTY, 2000).

Doherty (2000) aponta, ainda, o papel da economia da informação no entendimento da gestão de riscos. Quando os gestores começam a proteger a empresa dos eventos que estão fora do controle da administração, o resultado da empresa torna-se uma proxy mais realista do desempenho de seu core business. É como se a empresa isolasse seu resultado do restante do ambiente econômico. Naturalmente, os administradores das empresas mais lucrativas em seus ramos de atividade tenderiam a buscar proteção para aumentar seus salários e benefícios. Isso ocorreria porque o mercado descontaria mais generosamente os resultados operacionais dessas empresas do que os resultados respectivos de empresas menos afortunadas. De forma resumida: gestores competentes, em empresas lucrativas, tendem a proteger o resultado da empresa de quaisquer eventos extraordinários que possam causar problemas. Isso decorre do fato de que esses administradores sabem que suas empresas são lucrativas dentro de suas atividades operacionais. É uma forma de limpar o resultado.

Dentro da análise de Doherty (2000), a gestão de riscos é somente uma forma de reduzir os custos de transação. Esses custos, no entanto, podem ser reduzidos por intermédio de outras ações como, por exemplo, a alteração da estrutura de capital da empresa. Essa ação pode, em um mercado imperfeito, reduzir o custo de capital da empresa em situações em que os sinistros forem severos.

É relevante notar que o primeiro passo, dentro da análise exposta, é mensurar adequadamente os riscos relacionados com os eventos econômicos sob análise. Muitas vezes, o maior prejuízo que uma empresa tem com um sinistro não está ligado diretamente à perda de um ativo, mas, sim, às opções de crescimento e investimento que são desperdiçadas devido ao prejuízo causado pelo evento. Após uma grande perda, as decisões que a empresa tem que tomar, relativamente aos seus investimentos e ao financiamento, mudam ligeiramente de caráter. Ao invés de decidir sobre a aquisição de novos ativos, a empresa deve decidir se vai reestruturar suas operações ou, simplesmente, começar tudo de novo. O custo de reposição de um ativo pode suplantar os seus benefícios futuros inviabilizando a sua aquisição. A assimetria informacional pode ser uma causa da dificuldade da empresa de encontrar novas fontes de financiamento. Alguns instrumentos financeiros podem ser usados com essa finalidade. Os instrumentos híbridos de capital e dívida, debêntures conversíveis em ações, por exemplo, são meios para garantir aos credores que a empresa será administrada dentro de critérios previamente acordados.

Shimpi (2001) propôs um conceito de gestão de riscos diferenciado. Para esse autor, o ponto chave de uma gestão de riscos, realmente eficaz, é a 
integração. Os riscos devem ser avaliados de baixo para cima (bottom-up approach) de forma a integrar uma perspectiva corporativa para a gestão de riscos. Segundo o autor, o arcabouço conceitual da gestão de riscos está centrado na alocação eficiente de capital. Não há sentido na gestão de riscos que não promova uma alocação superior do capital investido na empresa. Com base nesses conceitos fundamentais, o autor foca os três principais players da gestão de riscos: o gestor de riscos (que está envolvido com o mercado segurador), o tesoureiro e o diretor financeiro (ambos estão mais diretamente ligados com o mercado financeiro e de capitais) ${ }^{1}$. Assim, pode ser estabelecida uma estrutura comum: o modelo de proteção agregado ${ }^{2}$ capaz de combinar as três funções desempenhadas por esses agentes dentro de uma estrutura comum. O modelo será apresentado em detalhes no decorrer deste texto.

Segundo Antunovich et al. (1999) a gestão de riscos é fundamental para as organizações modernas porque reduz a volatilidade dos resultados. Os autores citam que as empresas norte-americanas gastam US\$ 5.25 em atividades de proteção ao risco por cada mil dólares de vendas. Além das questões apresentadas por Doherty (2000), os autores comparam a estabilidade do lucro com a reputação das empresas medida pela revista Fortune no America's Most Admired Companies. Os autores do estudo concluem que as empresas mais admiradas são aquelas que apresentam resultados mais estáveis. Esses resultados apresentam uma nova dimensão para a importância da gestão de riscos: empresas bem sucedidas apresentam resultados mais estáveis do que empresas mal sucedidas. $O$ autor indica as ações tradicionais de evitar os riscos, reduzi-los, transferi-los ou, finalmente, retê-los como parte do tratamento tradicional para a gestão de riscos.

Tradicionalmente, a gestão de riscos é tratada de forma segregada da gestão financeira nas empresas e pela teoria de finanças. Essa abordagem não é a mais adequada porque ignora as inter-relações entre a gestão de riscos e a função financeira (LAMMTENNANT, 2002). A próxima seção apresenta uma abordagem alternativa para o problema da gestão de riscos nas organizações.

\section{UMA NOVA ESTRUTURA PARA A GESTÃO DE RISCOS}

De acordo com Doherty (2000:11), um modelo de gestão de riscos integrado teria as seguintes características:

a) Ser diagnóstico: o primeiro aspecto de uma gestão integrada de riscos refere-se ao seu aspecto preditivo em termos de custos para a organização. Muitas vezes a remoção das causas dos riscos é impraticável, por estarem muito ligados à atividade principal da empresa. A remoção pura e simples dos impactos do risco, contratação de um seguro, por exemplo, é, freqüentemente, muito cara. A organização precisa entender como o risco destrói valor. Com esse entendimento, os gestores podem agir diretamente nos problemas causados pelo risco. $O$ caráter preditivo do modelo passa, necessariamente, pelo entendimento da relação dos riscos com o valor da empresa.

b) Ser desenhado para possibilitar uma política de otimização de investimentos: os efeitos do risco podem levar a empresa a realizar uma alocação não ótima de seus ativos. Isso pode ocorrer devido à ausência de recursos para aproveitar novas oportunidades de investimento como conseqüência do sinistro. Outra causa de alocação imprópria de investimentos referese aos conflitos entre administradores, credores e acionistas que podem levar a empresa a decisões que destroem valor ao invés de criálo. Assim, a gestão de riscos deve considerar essa realidade e tomar as medidas necessárias para garantir o financiamento da empresa após os sinistros, bem como todas as medidas para o chamado financiamento contingente, ou seja, estratégia de financiamento levando em consideração a ocorrência de eventos incertos no futuro. O sucesso das decisões da empresa ligadas aos eventos segurados garante que a gestão de riscos será realmente eficaz em seu objetivo de garantir a criação de valor para a empresa;

\footnotetext{
${ }^{1}$ Em muitas organizações essas duas últimas funções podem estar centralizadas em um único indivíduo.

${ }^{2}$ Tradução livre do autor para a expressão insurative model.
} 
c) Ser baseado nos custos de transação: o risco pode potencializar os custos de transação da empresa. Na maioria dos países, as empresas são tributadas por intermédio de uma função convexa. Isso significa que a carga tributária aumenta de acordo com os lucros da empresa de forma não linear. Isso ocorre porque o valor esperado dos tributos para empresas com lucros mais voláteis é maior do que o valor esperado dos tributos para empresas com lucros mais estáveis. $O$ exemplo a seguir, extraído de Doherty (2000, p.201), clarifica essa questão.

Considere a empresa Tax com lucros que seguem a seguinte distribuição:

\begin{tabular}{cc}
\hline Lucros & Probabilidade \\
0 & 0,2 \\
100 & 0,3 \\
200 & 0,3 \\
300 & 0,2 \\
\hline
\end{tabular}

Assim, o valor esperado de seu lucro $E(L)=150$. Supondo que a empresa esteja sob uma alíquota única de $34 \%$ mas, devido às despesas dedutíveis e outras considerações, os 'primeiros' $\$ 120$ de resultado não seja tributados. Dessa forma, o lucro da empresa após os tributos está apresentado na tabela abaixo:

\begin{tabular}{rc} 
Cálculo & Lucro Após os tributos \\
$0-0$ & 0.0 \\
$100-0$ & 100.0 \\
$200-0,34(200-120)$ & 172.8 \\
$300-0,34(300-120)$ & 238.8 \\
\hline
\end{tabular}

Dessa forma, o valor esperado do resultado após os tributos será de $\$ 129,60$. Supondo que a empresa pudesse proteger sua posição com um derivativo que garantisse que os seus lucros futuros fossem iguais ao valor esperado $(\$ 150)$, os lucros após os tributos da empresa seriam de:

$$
150-0,34(150-120)=139,80
$$

O que representa um ganho de $\$ 10,20$. Essa abordagem não seria válida em uma situação na qual a empresa pudesse compensar seus prejuízos integralmente (adequadamente corrigidos) contra lucros futuros. Nesse caso, a função tributária da empresa seria uma linha reta e não uma função convexa. A discussão apresentada, nesse exemplo, está focada nos custos de transação relacionados com o cenário tributário. Conforme discutido anteriormente, o risco de insolvência, os conflitos entre administradores, acionistas e gestores etc, também contribuem para aumentar os custos de transação relacionados com a existência do risco.

d) Ser amplo: uma empresa pode tornar-se insolvente devido às catástrofes naturais que destruíram suas máquinas e equipamentos, erros operacionais ligados à execução de suas ordens de compra e venda de títulos mobiliários, flutuações nas taxas de juros e câmbio, entre muitos outros fatores (Doherty, 1997). Uma gestão de riscos integrada deve considerar esses fatores de forma ampla e consolidada e não somente estar focada em um único elemento.

e) Ser coordenado: riscos não podem ser algebricamente somados. A empresa precisa considerar as correlações entre esses riscos com o objetivo de pesá-las no momento do cálculo da exposição geral e ampla da empresa. A diversificação reduz o impacto final dos riscos na carteira da empresa.

Essas considerações iniciais levam claramente a uma estrutura para o desenvolvimento de um modelo integrado de gestão de riscos que esteja fundamentado na teoria econômica da firma. Shimpi (2001) desenvolve os conceitos acima buscando a integração entre a gestão de riscos tradicional (financeira) e a gestão de seguros. O modelo de proteção agregado tem essa finalidade. Inicialmente, é necessária a caracterização do papel do capital corporativo nas empresas e sua relação com o risco. Em seguida, os dois modelos de capital corporativo são apresentados: um relacionado com a estrutura tradicional do capital próprio e de terceiros (estrutura de capital tradicional) e outro relacionado com o mercado de seguros. Esses modelos são combinados para gerar o modelo de proteção agregado.

\section{O PAPEL DO CAPITAL CORPORATIVO}

Uma empresa precisa de capital para três finalidades básicas:

Capital Operacional: esse é o capital necessário para financiar as suas atividades operacionais. Se uma empresa somente realizar projetos sem risco (como comprar somente títulos governamentais para 
um banco de investimentos), ela somente precisará do valor do dinheiro no tempo necessário para custear os projetos. Não há necessidade de capital adicional ao intrinsecamente necessários para o custeio dos desembolsos relativos à atividade em questão.

Capital de Risco: essa caracterização do capital é necessária em adição ao capital operacional para cobrir as conseqüências dos riscos gerados pelas atividades operacionais da empresa. O montante depende da tolerância ao risco da empresa e é o montante que garante que a probabilidade de ruína da empresa fique abaixo de um nível determinado. Assumindo que a análise estatística da exposição do risco de uma empresa mostre que o seu capital operacional esperado é de \$500 milhões, mas que existe uma chance de $5 \%$ que ela necessite de $\$ 750$ milhões e uma chance de $1 \%$ de que ela necessite de $\$ 1$ bilhão, nesse caso, \$250 milhões adicionais garantem uma probabilidade de sobrevivência de $95 \%$ e $\$ 500$ milhões adicionais garantem uma probabilidade de sobrevivência de $99 \%$. Assim, o capital econômico da empresa pode ser definido:

\section{Capital econômico = capital operacional + capital de risco}

Capital de sinalização: os administradores estimam o capital econômico necessário à gestão das atividades da empresa. No entanto, existe uma assimetria informacional entre os administradores da empresa e os analistas de mercado. Esses analistas, por falta de informações tão detalhadas quanto aquelas à disposição dos administradores, utilizam modelos mais conservadores para avaliar o capital necessário à operação econômica da empresa. Dessa forma, os administradores acabam por manter mais capital do que o necessário para sinalizar ao mercado sua real situação financeira. A política de gestão de riscos é uma forma de sinalizar ao mercado a solidez da situação financeira da empresa, reduzindo, assim, a necessidade do capital de sinalização. Naturalmente, o montante do capital de sinalização depende das características do mercado em termos de eficiência informacional. Quanto mais eficiente o mercado nesse aspecto, menor será a necessidade de capital de sinalização. O capital de sinalização é uma espécie de desperdício do ponto de vista da alocação eficiente de recursos, uma vez que esse não seria necessário se o mercado incorporasse imediatamente toda a informação sobre a empresa. Assim, o capital necessário pode ser definido:

$$
\begin{gathered}
\text { Capital necessário = capital econômico + } \\
\text { capital de sinalização }
\end{gathered}
$$

Cabe aqui uma ressalva importante a respeito do conceito de capital dentro da estrutura de Shimpi. O autor divide o capital em capital efetivamente pago ou integralizado (paid-up capital) e capital fora do balanço (off-balance-sheet). O capital integralizado é aquele que efetivamente aparece nas demonstrações contábeis da empresa podendo ser efetivado em dinheiro ou outro ativo tangível $^{3}$. O capital off-balance pode ser dividido em dois componentes:

Direito de acessar capital se necessário: esse componente refere-se às facilidades que a empresa possui de acessar fontes de capital quando da ocorrência de sinistros e outros eventos relacionados ao risco sendo protegido. É uma espécie de capital contingente.

Transferência de risco para uma outra parte: esse componente refere-se ao risco que foi transferido para outras instituições de forma a liberar a empresa da manutenção do capital respectivo.

Assim, pode-se definir o capital e o risco da firma:

$$
\begin{gathered}
\text { Capital da firma }=\text { capital pago }+ \\
\text { capital fora do balanço }
\end{gathered}
$$

Risco da firma $=$ risco retido + risco transferido

Essa alocação de capital deve ser ótima. O capital em excesso leva à sub-utilização do capital e, conseqüentemente, a retornos menores para os acionistas. A falta de capital demonstra que a empresa assumiu riscos superiores àqueles que poderiam ser razoavelmente suportados. Essa relação entre os riscos assumidos e o capital necessário é a base do modelo proposto por Shimpi.

Os estudos tradicionais de estrutura de capital em finanças tratam dos direitos dos fornecedores de capital de acordo com suas prerrogativas legais (capital próprio versus terceiros). O nível de exposição ao risco depende do tipo de capital fornecido. O principal

${ }^{3}$ Como não existe uma estrutura eficaz para a mensuração de ativos intangíveis esses não entram no cômputo do capital necessário às operações da empresa. 
foco do estudo, dentro dessa linha, está na razão entre o capital próprio e o de terceiros. Essa teorização não considera outras fontes de capital. O capital off-balance é desconsiderado. Somente o capital efetivamente pago é considerado. Assim:

\section{Capital pago $=$ capital necessário para cobrir os riscos retidos}

Por outro lado, o modelo de seguros está focado na transferência de riscos. A gestão de riscos por intermédio dos seguros tem sido uma função segregada da área financeira nas empresas. Essa visão não é adequada. O modelo de seguros transfere os riscos para outras organizações (normalmente seguradoras) ao invés de prover um montante de capital para cobrir a ocorrência dos seguros, como faz o modelo da estrutura de capital tradicional em finanças. Dessa forma:

Capital fora do balanço $=$ capital necessário para cobrir os riscos sendo transferidos

O modelo de seguros está focado nos riscos sendo transferidos e no custo de tal ação. O capital liberado por tal ação não é explicitamente considerado. Assim, pode-se definir o capital total da firma:

Capital total da firma = dívida + próprio + segurado

\section{O MODELO DE PROTEÇÃO AGREGADO}

A extensão dessas idéias é direta. A combinação das idéias apresentadas acima resulta na seguinte estrutura para o capital da firma:

Capital da firma = capital necessário para cobrir os riscos da firma

Capital Integralizado + capital fora do balanço $=$ risco retido + risco transferido

Esse modelo é mais rico conceitualmente do que o modelo tradicional de finanças e do que o modelo de seguros. Essa estrutura conceitual apresentada por Shimpi (2001) não trata diretamente do problema da mensuração desses riscos. A mensuração desses riscos não está no escopo deste trabalho. TrabaIhos como os de Bowers et al. (1986) e Jorion (1996) tratam desses temas.

Apesar do caráter integrativo desse modelo, a sua eficácia organizacional dependerá do papel do gestor de risco nas organizações. O Chief Financial Officer (Diretor Financeiro) deve estar adequadamente treinado e propenso a permitir a referida integração.

\section{CONCLUSÕES E IMPLICAÇÕES PARA FUTURAS PESQUISAS}

Neste trabalho foi apresentada uma estrutura alternativa para o entendimento da gestão de riscos nas organizações contemporâneas. O papel da gestão de riscos é entendido dentro de uma perspectiva que enfatiza os custos de transação referentes à não cobertura dos ativos em risco. A literatura tradicional, que ignora os custos de transação, não explica adequadamente a existência de ações de gestão de risco nas organizações. Dentro dessa perspectiva, as ações de gestão de riscos tradicionais (financeiras) podem ser integradas com o modelo de seguros gerando um modelo de proteção agregado. Estudos futuros podem explorar vários aspectos do problema analisado neste trabalho. Inicialmente, estudos empíricos poderiam investigar o volume de atividades de hedge em comparação com os custos de transação em diferentes mercados. Esse tipo de estudo poderia fornecer uma base mais sólida para o entendimento do papel da gestão de riscos nas organizações. Outro aspecto relevante refere-se à mensuração dos diversos riscos e a integração dos mesmos. Esse aspecto é fundamental para que a integração proposta possa ser efetivamente implementada. É importante frisar que este trabalho não apresenta conclusões analíticas (dentro do enfoque positivo de pesquisa), sendo somente uma visão alternativa do desenvolvimento dos estudos em gestão de risco. Procura-se, com essa dimensão, abrir caminho para pesquisas futuras na área.

A questão do risco operacional merece atenção especial nesse cenário. A dificuldade de mensurar esse risco, em comparação com o financeiro, torna sua integração com os demais riscos mais difícil. O risco operacional pode ter correlação com outros riscos segurados (comumente associados com os seguros de lucros cessantes). Outro aspecto relevante referese às questões organizacionais referentes à implementação de modelos de risco integrados em estruturas administrativas mais rígidas. 


\section{REFERÊNCIAS BIBLIOGRÁFICAS}

ANTUNOVICH, Peter, LASTER, David S. Do investors mistake a good company for a good investment? Federal Reserve Bank of New York: Staff Reports 60, 1999.

BARTON, J. Does the Use of Financial Derivatives Earnings Management Decisions? The Accounting Review, Vol. 76, № 1 , January 2001.

BOWERS R. et al. Actuarial Mathematics. Illinois: Society of Actuaries, 1986.

DOHERTY, Neil A. Innovations in managing catastrophe risk. The Journal of Risk and Insurance, Vol. 64, № 4, December, 1997.

DOHERTY, Neil A. Integrated Risk Management. New York: McGraw Hill, 2000.

JORION, Philipe. Value at Risk. Wiley Series in Finance, 1996.
KOTHARI, S. P. Discussion of "the relation between analysts' forecasts of long-term earnings growth and stock price performance following equity officering". Contemporary Accounting Research, Vol. 17, N 1, Spring, 2000.

LAMM-TENNANT, Joan. Implications of extreme events and market shocks: capacity, price volatility and the value of transparency. <http://www.Ideo.columbia.edu/res/pi/CHRR/ Roundtable/ LammTennant_Joan_Note.pdf>. Acesso em 07/11/2003.

SHIMPI, Prakash. Integrating Corporate Risk Management. Texere, 2001.

VAUGHAN, Emmett J. Risk mangement. John Wiley \& Sons, Ins., 1997.

\section{BIBLIOGRAFIA COMPLEMENTAR}

BEAVER, William H. \& PARKER, George. Risk Management. Problems and Solutions. Financial Research Initiative. Stanford University: McGraw Hill, 1995.

CARVALHO, Luiz Nelson Guedes. Uma Contribuição para a Auditoria de Risco de Derivativos. 1996. Tese (Doutorado em Controladoria e Contabilidade) - Faculdade de Economia, Administração e Contabilidade da USP, Universidade de São Paulo, São Paulo.

FRost, C.; ALLEN, D.; PORTER, J.; BLOODWORTH, P. Operational Risk and Resilience - understanding and minimizing operational risk to secure shareholder value. Prince Water House Coopers, Betterworth Heinemann: Oxford, 2001.
LIMA, Iran Siqueira; LOPES, Alexsandro Broedel. Contabilidade e Controle de Operações com Derivativos. São Paulo: Pioneira, 1999.

LOOMIS, C. J. Lies, damned lies, and managed earnings: the crackdown is here. Fortune, p.75-92, August 2.

LOPES, Alexsandro Broedel; LIMA, Iran Siqueira. Perspectivas para a Pesquisa em Contabilidade: o impacto dos derivativos. Revista de Contabilidade \& Finanças - USP, São Paulo, n. 26, p. 25-42, maio-agosto/2001.

MARSHAL, C. Measuring and Managing Operational Risks in Financial Institutions. Wiley Series in Finance, London, 2001.

NOTA:

Endereço dos autores:

ALEXSANDRO BROEDEL LOPES

Av. Prof. Luciano Gualberto, 908

05508-900 - São Paulo - Brasil

L. NELSON CARVALHO

Av. Prof. Luciano Gualberto, 908

05508-900 - São Paulo - Brasil

ARIDELMO JOSÉ CAMPANHARO TEIXEIRA

Rua Moacir Ávidos, 247/201

29057-230 - Vitória - Brasil 